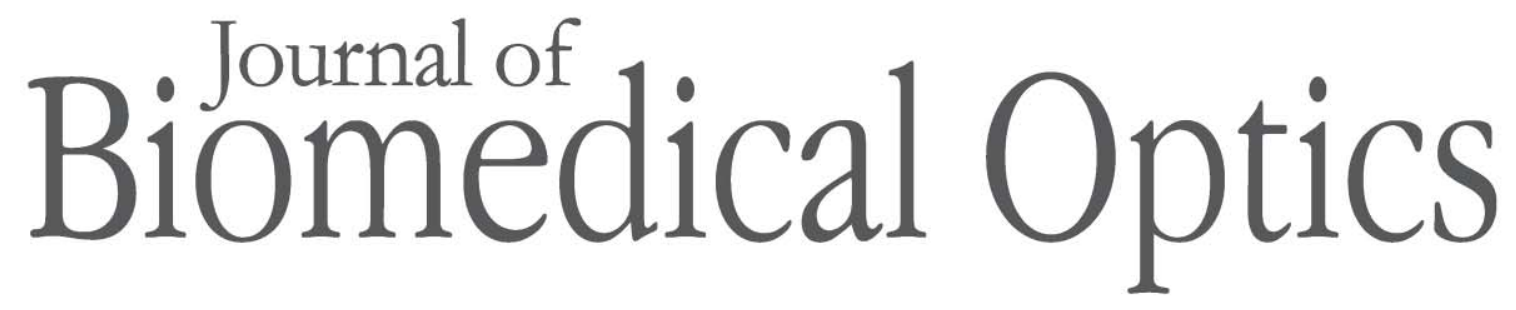

\title{
Poly(vinyl alcohol) gels as photoacoustic breast phantoms revisited
}

Wenfeng Xia

Daniele Piras

Michelle Heijblom

Wiendelt Steenbergen

Ton G. van Leeuwen

Srirang Manohar 


\title{
Poly(vinyl alcohol) gels as photoacoustic breast phantoms revisited
}

\author{
Wenfeng Xia, ${ }^{a, *}$ Daniele Piras, ${ }^{\mathrm{a}, *}$ Michelle Heijblom, ${ }^{a}$ Wiendelt Steenbergen, ${ }^{\mathrm{a}}$ Ton G. van Leeuwen, ${ }^{\mathrm{a}, \mathrm{b}}$ \\ and Srirang Manohar ${ }^{a}$ \\ a University of Twente, Biomedical Photonic Imaging group, Mira Institute for Biomedical Technology and Technical \\ Medicine, P.O. Box 217, 7500AE Enschede, The Netherlands \\ bUniversity of Amsterdam, Biomedical Engineering and Physics, Academic Medical Center, P.O. Box 2270, \\ 1100 DE Amsterdam, The Netherlands
}

\begin{abstract}
A popular phantom in photoacoustic imaging is poly(vinyl alcohol) (PVA) hydrogel fabricated by freezing and thawing $(\mathrm{F}-\mathrm{T})$ aqueous solutions of PVA. The material possesses acoustic and optical properties similar to those of tissue. Earlier work characterized PVA gels in small test specimens where temperature distributions during F-T are relatively homogeneous. In this work, in breast-sized samples we observed substantial temperature differences between the shallow regions and the interior during the F-T procedure. We investigated whether spatial variations were also present in the acoustic and optical properties. The speed of sound, acoustic attenuation, and optical reduced scattering coefficients were measured on specimens sampled at various locations in a large phantom. In general, the properties matched values quoted for breast tissue. But while acoustic properties were relatively homogeneous, the reduced scattering was substantially different at the surface compared with the interior. We correlated these variations with gel microstructure inspected using scanning electron microscopy. Interestingly, the phantom's reduced scattering spatial distribution matches the optical properties of the standard two-layer breast model used in $x$ ray dosimetry. We conclude that large PVA samples prepared using the standard recipe make excellent breast tissue phantoms. ( 2011 Society of Photo-Optical Instrumentation Engineers (SPIE). [DOI: 10.1117/1.3597616]
\end{abstract}

Keywords: photoacoustic; poly(vinyl alcohol) gel; breast phantom; scanning electron microscope.

Paper 11056RR received Feb. 4, 2011; revised manuscript received May 12, 2011; accepted for publication May 16, 2011; published online Jul. 6, 2011.

\section{Introduction}

Tissue mimicking phantoms are important for the evaluation of the performance characteristics of an imaging system, such as resolution, sensitivity, and imaging depth. ${ }^{1}$ Most phantoms are designed for the testing of one particular imaging modality. Photoacoustics is an intrinsically hybrid approach which is characterized by light and sound propagation; applied pulsed light excites ultrasound from absorbing structures, such as blood vessels and angiogenic tumor masses, which can be detected. The advantages and various applications of photoacoustic (PA) imaging have been reviewed by Wang. ${ }^{2}$ One of the important applications is photoacoustic breast imaging, an area of intense research interest, ${ }^{3-6}$ as a promising alternative technology to detect angiogenic markers of breast cancer based on hemoglobin absorption. Phantoms for PA breast imaging have to be designed to accomplish both optical and acoustic properties of soft tissues.

Poly(vinyl alcohol) (PVA) gels were introduced as photoacoustic phantoms by Kharine et al. ${ }^{7,8}$ and used by several groups for photoacoustic imaging 9,10 and optical elastography. ${ }^{11}$ PVA gels are formed by the physical crosslinking of hydroxyl groups by hydrogen bonding in the process of freezing and thawing $(\mathrm{F}-\mathrm{T})$. The $\mathrm{F}-\mathrm{T}$ process promotes the formation of crystallites in an amorphous matrix. ${ }^{12}$ The number, size, and stability of crystallites are increased with an increasing number

*These authors contributed equally to the work.

Address all correspondence to: Srirang Manohar, University of Twente, Drienerlolaan 5-Enschede, Overijssel 7522DB Netherlands; Tel: +31-(0)53-4893164; Fax: +31(0)53-489-1105. E-mail: s.manohar@utwente.nl. of F-T cycles by which the mechanical strength of the gel increases. ${ }^{12,13}$ Therefore, no additional chemical agents are required for gelation. Such gels were used earlier to mimic soft tissues in ultrasound ${ }^{14,15}$ and magnetic resonance imaging. ${ }^{16,17}$ Kharine et al. ${ }^{7}$ found that repeated F-T also led to increased light scattering in the gel. During freezing, the gel is separated into an ice phase and a polymer phase. A significant volume expansion takes place in the formation of the ice phase, leaving pores during thawing which causes refractive index fluctuations, and hence optical scattering. Kharine et al. ${ }^{7}$ optimized the number of F-T cycles and thereby controlled the optical characteristics of the resulting gel to match values quoted for breast tissue. Coupled with the favorable acoustic properties, the gels were found to be excellent photoacoustic phantoms. ${ }^{18}$

Various properties of the hydrogels depend on the specifications of the $\mathrm{F}-\mathrm{T}$ processing that they undergo, such as the number of $\mathrm{F}-\mathrm{T}$ cycles, the durations of $\mathrm{F}-\mathrm{T}$, the rates of $\mathrm{F}-$ $\mathrm{T}$ and the actual temperatures attained. ${ }^{19,20}$ While Kharine et $\mathrm{al}^{7}$ studied only the effect of the number of F-T cycles on the phantom properties, the influence of the other variables is not known. The actual temperature achieved and the rates of F-T experienced depend on the sizes of the gel produced and for the large phantoms required for breast imaging, these are expected to be spatially nonuniform. These spatial temperature responses could have an effect on the relevant phantom properties, which if not taken into account could cause inaccurate estimation of performances of the PA imaging system.

1083-3668/2011/16(7)/075002/10/\$25.00 @ 2011 SPIE 


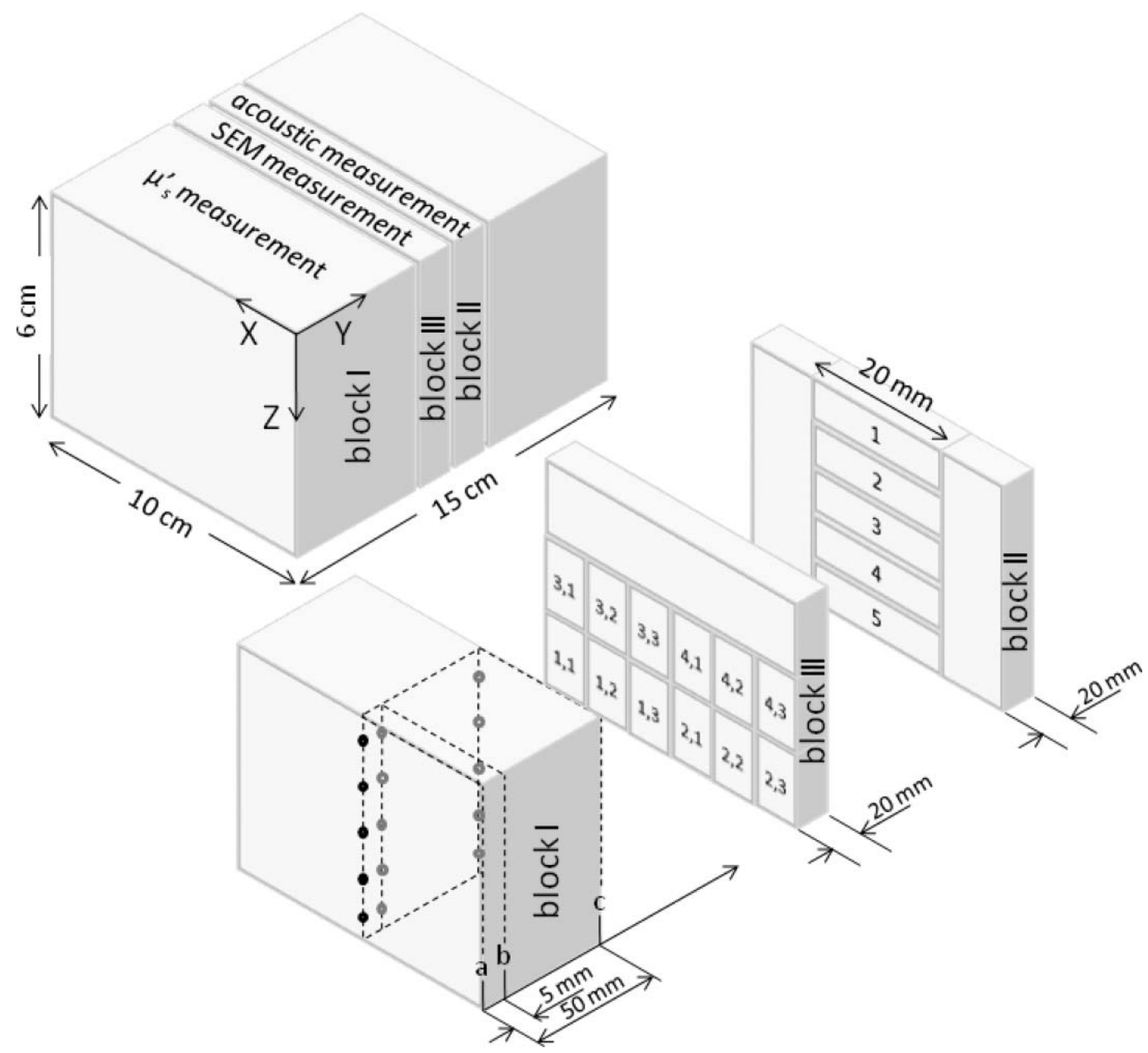

Fig. 1 Schematic of poly(vinyl alcohol) gel prepared for speed of sound, acoustic attenuation, optical reduced scattering coefficient, and microstructure measurements.

In this work, we investigate the spatial distribution of phantom properties in a large PVA breast sample. We study the distribution of reduced scattering coefficient $\left(\mu_{s}^{\prime}\right)$, speed of sound (SOS), and acoustic attenuation (AA) in the phantom. These properties are discussed in the context of spatial temperature variations monitored during the $\mathrm{F}-\mathrm{T}$ process and correlated with the microstructure examined with scanning electron microscopy (SEM). We then discuss the suitability of the breast samples as phantoms for photoacoustic mammography.

\section{Materials and Methods}

\subsection{PVA Phantom Preparation}

The recipe for making PVA gel-based phantoms has been described in Kharine et al. ${ }^{7}$ and Manohar et al. ${ }^{18}$, here we briefly summarize the procedure. PVA with a hydrolysis degree greater than $99 \%$ and an average molecular weight of 85, 000 to 140, 000 (Sigma-Aldrich, catalog no. 36 314-6) is used. An aqueous solution of 20 wt. \% PVA is obtained by dissolving PVA powder in demineralized water at $95^{\circ} \mathrm{C}$ with continuous gentle stirring for $2 \mathrm{~h}$. After it is allowed to stand for a few hours to let air bubbles migrate to the surface, the solution is cast in a Perspex mold and kept for $12 \mathrm{~h}$ at $-20^{\circ} \mathrm{C}$ in a refrigerator and subsequently for $12 \mathrm{~h}$ at room temperature.
This constitutes one F-T cycle. The final sample is prepared undergoing four F-T cycles according to Kharine et al. ${ }^{7}$

A large PVA phantom prepared with dimensions of $15 \times 10 \times 6 \mathrm{~cm}^{3}$, is divided into three blocks (Fig. 1). Block I is used for measuring the $\mu_{s}^{\prime}$ (Sec. 2.3). Block II is used for acoustic property measurements (Sec. 2.4). Block III is used for the microstructure study with SEM (Sec. 2.5).

\subsection{Temperature Measurements}

The temperature at two different locations (at the surface and $30 \mathrm{~mm}$ under the surface) inside the PVA gel during F-T cycles is simultaneously recorded using two K-type thermocouples (Rössel Messtechnik, Dresden, Germany).

\subsection{Reduced Scattering Coefficient Assessment}

A custom-made setup based on the principle of obliqueincidence diffuse reflectance (ODR) is used to measure the reduced scattering coefficient $\left(\mu_{s}^{\prime}\right)$. The method is discussed in detail by Wang and Jaques, ${ }^{21}$ for a semi-infinite sample with $\mu_{s}^{\prime}$ much larger than the absorption coefficient $\mu_{a}$. Under these assumptions, a narrow beam incident obliquely on the surface can be approximated by a buried isotropic point source that is 


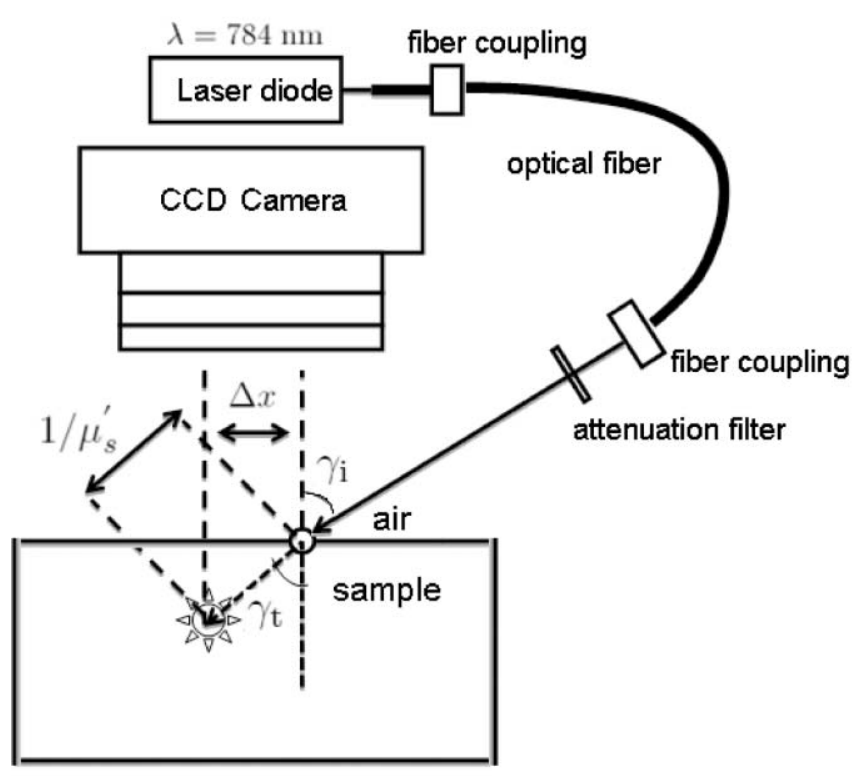

(a)
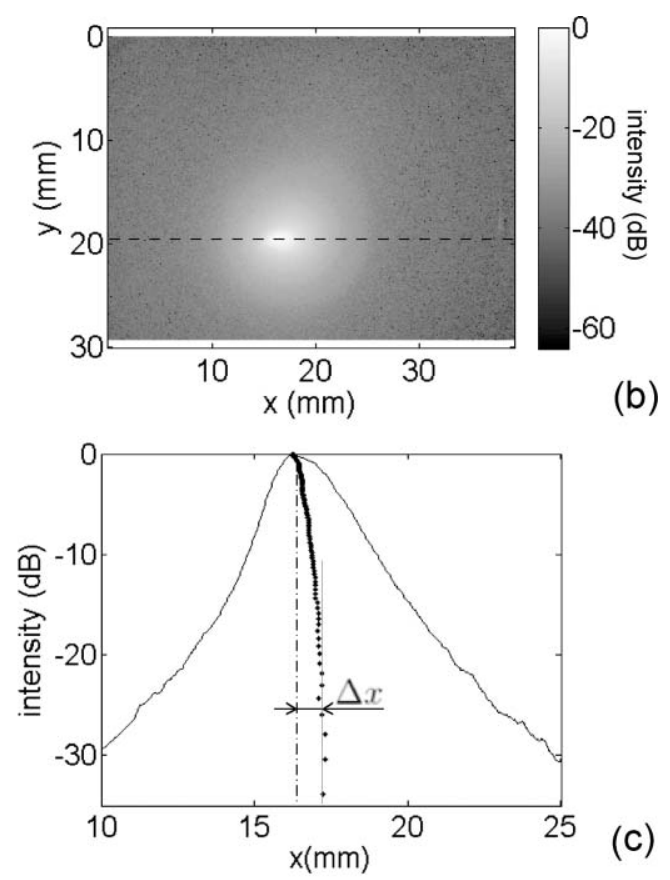

Fig. 2 (a) Schematic of the oblique-incidence diffuse reflectance principle and setup. (b) Diffuse reflectance intensity map. (c) Diffuse reflectance profile (solid curve), calculated midpoint curve (dotted), and light entry point (dashed-dotted) at the position indicated in dashed line in (b).

$1 / \mu_{s}^{\prime}$ away from the incident point [see Fig. 2(a)]. The center of the diffuse reflectance is shifted from the center of the incident beam by $\Delta x$. From the diffuse reflectance intensity map [Fig. 2(b)], a profile is selected along the major axis of the elliptical spot [Fig 2(c)] from the edges of the reflectance profile at each intensity level. The spatial difference between the light entry point and the midpoint curve at saturation indicate the shift $\Delta x$. Considering also the refraction, $\Delta x$ is expressed as:

$$
\Delta x=\frac{\sin \left(\gamma_{\mathrm{t}}\right)}{\mu_{s}^{\prime}}
$$

where $\gamma_{t}$ is the refractive angle, calculated from the known incident angle $\gamma_{i}$ and refractive index of the sample $n$ by:

$$
\sin \left(\gamma_{\mathrm{i}}\right)=n \sin \left(\gamma_{\mathrm{t}}\right) .
$$

In our experimental setup, as shown in Fig. 2(a), a laser diode with excitation wavelength of $784 \mathrm{~nm}$ (Thorlabs, Newton, New Jersey) is used as a CW laser source. The laser beam is coupled through a $600-\mu \mathrm{m}$ fiber and collimated on the surface of the sample to obtain a beam diameter around $1 \mathrm{~mm}$. A CCD camera (Allied Vision Technologies, Stadtroda, Germany) is used to image the beam shape. A neutral density filter is used to attenuate the imaged light intensity and to prevent saturation of pixels. The fiber coupling unit and the collimating lens, together with the optical filter, are fixed on a custom-made aluminum arm, which can be rotated to adjust the incident angle of the laser beam. For every measurement, two images, with and without filter, are taken and an incident angle of $45 \mathrm{deg}$ is used.

A calibrated sample with known $\mu_{s}^{\prime}$ and refractive index $n$ is measured to validate our ODR system. This sample is based on epoxy resin with the optical scattering provided by adding a proper amount of $\mathrm{TiO}_{2}$ particles. ${ }^{22}$ Good agreement between the measured $\mu_{s}^{\prime}$ and reported value is obtained (Table 1). Further, $20 \%$ Intralipid (batch no. WI15893, Fresnius Kabi Nederland
$\mathrm{BV}$, The Netherlands) samples with concentration in water varying from $0.1 \%$ to $0.5 \%$ in volume were measured. As shown in Fig. 3, our measurements show good agreement with the reported values calculated from Van Staveren et al. ${ }^{23}$

The spatial distribution of $\mu_{s}^{\prime}$ within the PVA phantom is investigated by applying the ODR approach at different locations on three planes of block I as indicated in Fig. 1. Plane $a$ is the surface of the block, and plane $b$ is obtained by removing a $5 \mathrm{~mm}$ thick layer after measurements at plane $a$. Plane $c$ is the surface of the block opposite to plane $a$. Therefore, these three planes represent the depths of 0,5 , and $50 \mathrm{~mm}$ along the $Y$ axis. Each plane is investigated at 5 depths from 1 to $5 \mathrm{~cm}$ along the $Z$ axis ( 5 times averaging). Care was taken to enable that the diffuse reflectance beam lay well within the sample without interference from edges. A refractive index of 1.36 for the PVA specimens is used according to Kharine et al. ${ }^{7}$

\subsection{Speed of Sound and Acoustic Attenuation Assessment}

The acoustic transmission properties are measured using the insertion technique. ${ }^{24}$ A $5-\mathrm{MHz}$ unfocused single element

Table 1 Validation of the oblique-incidence diffuse reflectance system. The sample is calibrated at $800 \mathrm{~nm}$ and measured at $784 \mathrm{~nm}$. Five measurements are taken for the sample.

\begin{tabular}{lcc}
\hline & $\begin{array}{c}\text { Reduced scattering }\left(\mu_{s}^{\prime}\right) \\
\left(\mathrm{mm}^{-1}\right)\end{array}$ & $\begin{array}{c}\text { Reduced scattering }\left(\mu_{s}^{\prime}\right) \\
\left(\mathrm{mm}^{-1}\right)\end{array}$ \\
\hline Calibrated sample & $1.40 \pm 0.05^{\mathrm{a}}$ & $1.41 \pm 0.11^{\mathrm{b}}$ \\
\hline $\begin{array}{l}\text { a From Firbank and Delpy (Ref. 22). } \\
\text { bOur measurements. }\end{array}$
\end{tabular}




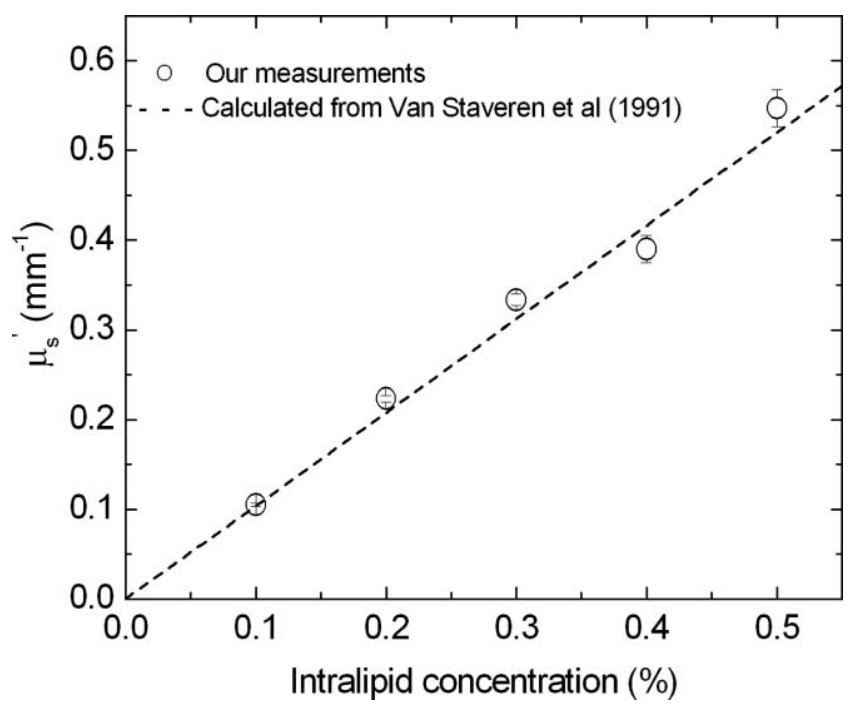

Fig. 3 Reduced scattering coefficient $\left(\mu_{s}^{\prime}\right)$ at $784 \mathrm{~nm}$ for varying Intralipid $20 \%$ concentrations in water measured using the obliqueincidence diffuse reflectance setup. Our results are compared with $\mu_{s}^{\prime}$ values calculated from Van Staveren et al. ${ }^{23}$ Each sample is measured 5 times, error bars represent standard deviations.

transducer (V309 Panametrics) and a broadband needle hydrophone (BLLMCX074 Precision Acoustic Ltd., Dorchester) are mounted in a demineralized water bath at room temperature (Fig. 4). The transducer is driven by a broadband ultrasonic pulser/receiver (Panametrics 5077PR) to emit an ultrasonic pulse whose frequency content is determined by the transducer center frequency and bandwidth $(2.25$ to $7.8 \mathrm{MHz})$. The measurement data are recorded with a data acquisition card (U1067A Acqiris, 8 bit, $500 \mathrm{MS} / \mathrm{s}$ ) while the water temperature is logged using a USB thermocouple measurement device (NIUSB TC01) with the K-type thermocouple. The temperature remained stable within $\pm 0.05^{\circ} \mathrm{C}$ during the measurement time of 5 min.

A reference signal is obtained when no sample is inserted between the transmitter and the receiver. The ultrasound pulse

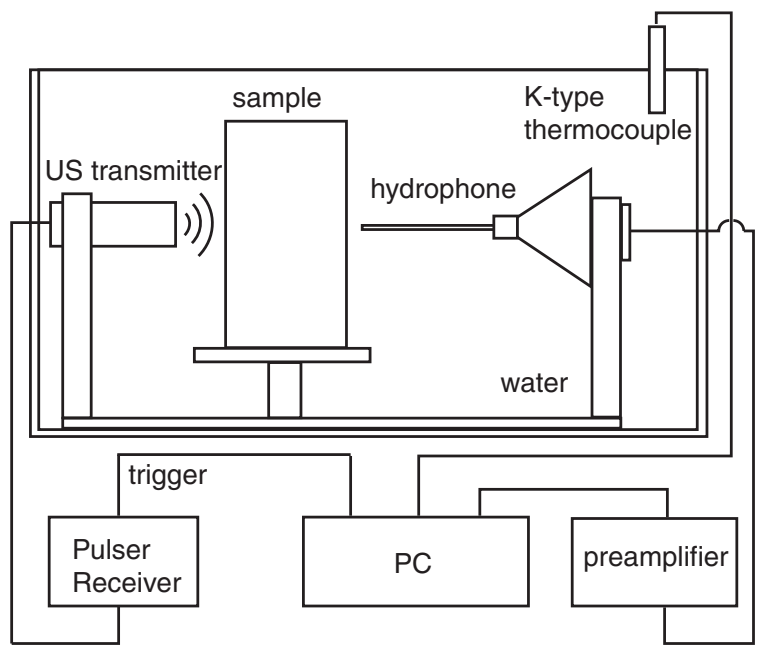

Fig. 4 Schematic of the setup for speed of sound and acoustic attenuation measurements. from the sample measurement has a time-of-arrival shift $\Delta T$ and amplitude decrease with respect to the reference signal. The thickness $\Delta d$ of each sample is measured several times around the position where the sample is insonified. For every sample the $\Delta d$ used in the estimation of the acoustic parameters is the mean \pm standard deviation of 10 measurements. Knowing the speed of sound in water $\left(C_{w}\right)$ at the measurement temperature, ${ }^{25}$ the frequency dependent SOS function $C_{S}(\omega)$ can be expressed in the frequency domain as:

$$
\frac{1}{C_{\mathrm{s}}(\omega)}=\frac{1}{C_{\mathrm{w}}}-\frac{\Delta \phi(\omega)}{\omega \Delta d}
$$

in which $\omega$ is the angular frequency, $\Delta \phi(\omega)$ is the phase difference between the FFT of the signals with and without sample insertion. Attenuation can be expressed as:

$$
\alpha_{\mathrm{s}}(\omega)=\alpha_{\mathrm{w}}-\frac{1}{\Delta d}\left[\ln A_{\mathrm{s}}(\omega)-\ln A_{\mathrm{w}}(\omega)\right]
$$

where $A_{\mathrm{i}}(\omega)$ is the amplitude in the frequency domain, and $\alpha_{\mathrm{i}}(\omega)$ the attenuation coefficient $\left(\mathrm{dB} \mathrm{cm} \mathrm{cm}^{-1} \mathrm{MHz}^{-1}\right)$ with $i$ $=s, w$ (sample, water). The attenuation of most materials follows a frequency power law: ${ }^{26}$

$$
\alpha_{\mathrm{s}}(\omega)=\alpha_{0}\left|\omega^{\mathrm{y}}\right|
$$

where $y$ is the power law factor assumed to be 1 as in most soft tissues, and $\alpha_{0}$ is the attenuation constant. SOS and AA can be estimated simultaneously by using the Kramers-Krönig (KK) relation fitting the power law to the frequency bandwidth of the transducer: ${ }^{27-29}$

$$
\frac{1}{C_{\mathrm{s}}(\omega)}=\frac{1}{C_{\mathrm{s}}\left(\omega_{0}\right)}+\alpha_{0} \tan \left(\frac{\pi}{2} y\right)\left(|\omega|^{\mathrm{y}-1}-\left|\omega_{0}\right|^{\mathrm{y}-1}\right) .
$$

From the data we sample both SOS and AA at the frequency of interest, namely $5 \mathrm{MHz}$. Errors due to interface losses will be minimized with this frequency domain approach since these are expected to be frequency independent.

The KK-based solver has been validated using two calibrated samples based on evaporated milk and agarose ${ }^{30-32}$ provided by E. L. Madsen (University of Wisconsin, Wisconsin). The sample thicknesses were measured to be $22.95 \pm 0.24 \mathrm{~mm}$ and 20.85 $\pm 0.15 \mathrm{~mm}$ for samples I and II, respectively. Good agreement is achieved between the measured SOS and AA with the calibrated values (Table 2).

Block II in Fig. 1 is used for the measurements. It is divided into five pieces with the same size of approximately $2 \times 2$ $\times 1 \mathrm{~cm}^{3}$. Therefore, these five samples are representative of depths from 1 to $5 \mathrm{~cm}$.

\subsection{Microstructure of PVA Gels}

Several authors ${ }^{33-35}$ have studied PVA hydrogel microstructure. However, their specific applications did not require the cast sample to exceed 3-mm thickness. For breast mimicking phantoms, characterization needs to be done on samples with thickness on the order of a few centimeters. 
Table 2 Calibrated $\left(22^{\circ} \mathrm{C}\right)$ and measured $\left(22.7^{\circ} \mathrm{C}\right)$ speed of sound and acoustic attenuation values for the two calibrated samples. Temperatures were stable within $\pm 0.05^{\circ} \mathrm{C}$ during the measurement time of 5 minutes. The mean and dispersions in measured thicknesses were used in the estimation.

\begin{tabular}{lccccc}
\hline & \multicolumn{2}{c}{ Calibrated } & & \multicolumn{2}{c}{ Measured } \\
\cline { 2 - 3 } \cline { 5 - 6 } $\begin{array}{l}\text { Sample } \\
\text { no. }\end{array}$ & $\begin{array}{c}\text { SOS } \\
\left(\mathrm{m} \mathrm{s}^{-1}\right)\end{array}$ & $\begin{array}{c}\text { AA @ } 5 \mathrm{MHz} \\
\left.(\mathrm{dB} \mathrm{cm})^{-1}\right)\end{array}$ & $\begin{array}{c}\text { SOS @ 5MHz } \\
\left(\mathrm{m} \mathrm{s}^{-1}\right)\end{array}$ & $\begin{array}{c}\text { AA @ 5MHz } \\
\left.(\mathrm{dB} \mathrm{cm})^{-1}\right)\end{array}$ \\
\hline I & $1559^{a}$ & $5.87^{a}$ & & $1564 \pm 1.0$ & $5.4 \pm 0.2$ \\
$\|$ & $1535^{a, b}$ & $2.67^{a, b}$ & & $1538 \pm 0.4$ & $2.4 \pm 0.1$ \\
\hline
\end{tabular}

aMadsen (2008) private communication.

bFrom Wear et al. (Ref. 32).

Trials were carried out to choose the optimum procedure for pore analysis. In samples prepared by critical point drying (CPD) ${ }^{33}$ and liquid nitrogen (LN2) treatment, ${ }^{34,36}$ SEM (FEI/Philips XL30 ESEM ${ }^{\mathrm{TM}}$ FEG, FEI Company, Hillsboro, Oregon) inspection showed 10 to $20 \mu \mathrm{m}$ cavities on the surface of the specimens (Fig. 5). However, under higher magnification of CPD treated samples [Fig. 5(a) inset], the structures appeared collapsed (see also Ref. 34). In LN2 treated samples [Fig. 5(b) inset], smaller cavities are further distinguishable. LN2 treatment is thus preferred since the pores are preserved, but also since it is fast. Further, the samples undergo spontaneous cracking into 2 or more fragments when quenched. This exposes the interiors avoiding the need for further cutting.

A 2-cm thick slice of the phantom, block III, is cut into four main blocks (Fig. 1, groups 1 to 4). Three specimens from each block are obtained (Fig. 1). Every specimen is inspected with SEM at different locations; average pore size is determined from 150 pores. The number of pores in a $5 \times 5 \mu \mathrm{m}^{2}$ region of interest $\left(A_{\mathrm{ROI}}\right)$ is counted for every specimen and is used to calculate the average wall thickness. From the number of pores $v$ and the average radius $\rho$, the total area occupied by assumed circular

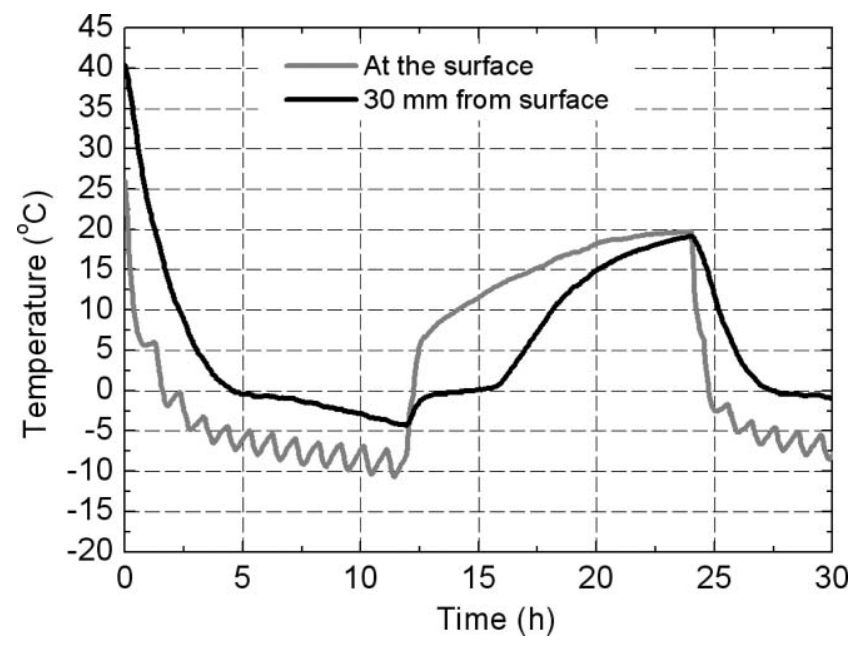

Fig. 6 Temperature recorded at the surface (gray line) and $30 \mathrm{~mm}$ under the surface (black line) of a large PVA phantom during F-T cycles.

pores is:

$$
A_{\mathrm{P}}=\nu \pi \rho^{2}
$$

The area of material surrounding each pore, on average, can be expressed as:

$$
A_{\mathrm{W}}=\frac{A_{\mathrm{ROI}}-A_{\mathrm{P}}}{v} .
$$

Finally, assuming the wall of each pore to be a circular ring, its thickness is given by:

$$
W=\sqrt{\frac{A_{\mathrm{W}}}{\pi}} .
$$

\section{Results}

\subsection{Temperature Measurements}

Temperatures measured at the surface and the inside of the large PVA phantom during F-T procedure are shown in Fig. 6. The
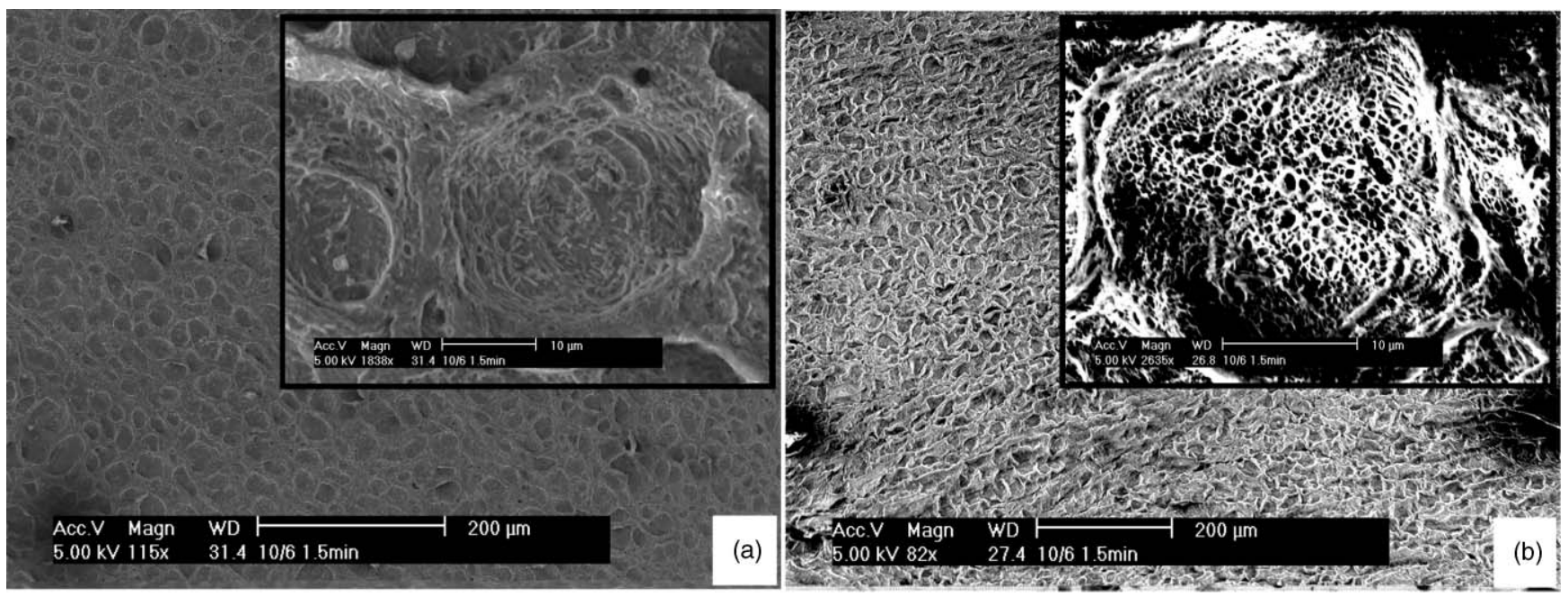

Fig. 5 Scanning electron microscopy of (a) outer surface of critical point during processed sample and (b) liquid nitrogen processed sample. 
aqueous PVA solution was allowed to stabilize for $2 \mathrm{~h}$ before submitting it to the $\mathrm{F}-\mathrm{T}$ procedure. At the instant when the exterior had cooled to room temperature, the interior was still warm. The thermocouple positioned close to the surface experiences the typical saw tooth temperature oscillations in the refrigerator produced by simple ON-OFF control exerted by the thermostat. The thawing cycle on the other hand shows a smooth temperature rise since this is not a thermostat controlled effect. The interior temperature lags the surface cooling, and at any instant in time is 5 to $10^{\circ} \mathrm{C}$ higher than the surface temperature. When the surface temperature reaches the freezing temperature of water, the bulk temperature is still about $15^{\circ} \mathrm{C}$. The outer layer of the PVA phantom thus starts freezing earlier than the inside. The same phenomenon occurs during thawing. Both the surface temperature and bulk temperature measured do not reach $-20^{\circ} \mathrm{C}$ when undergoing $12 \mathrm{~h}$ freezing.

\subsection{Reduced Scattering Coefficient}

The $\mu_{s}^{\prime}$ distribution inside the large PVA phantom is shown in Fig. 7. Three sets of measurements are performed for the three planes of block I (Fig. 1). The measured $\mu_{s}^{\prime}$ on the PVA surface is generally lower than that measured in the bulk. Both plane $a$ and plane $c$ measurements show that $\mu_{s}^{\prime}$ increases approaching the center of the phantom and the maximum $\mu_{s}^{\prime}$ inside the phantom is approximately 3 times larger than that on the surface. The $\mu_{s}^{\prime}$ from plane $c$ at depths from 1 to $5 \mathrm{~cm}$ has a maximum variation of less than $30 \%$. However, the largest variation is within the first few millimeters from the surface layer. Measurements from plane $b$ and plane $c$ show similar behavior.

The $\mu_{s}^{\prime}$ values of the large PVA phantom at different locations measured using the ODR technique are dependent on the refractive index $n$ of the sample. According to Kharine et al., ${ }^{7}$ a refractive index of 1.36 for PVA is used for $\mu_{s}^{\prime}$ calculation. Since the temperature distribution might affect the refractive index, we recalculated the $\mu_{s}^{\prime}$ using a refractive index in the range between

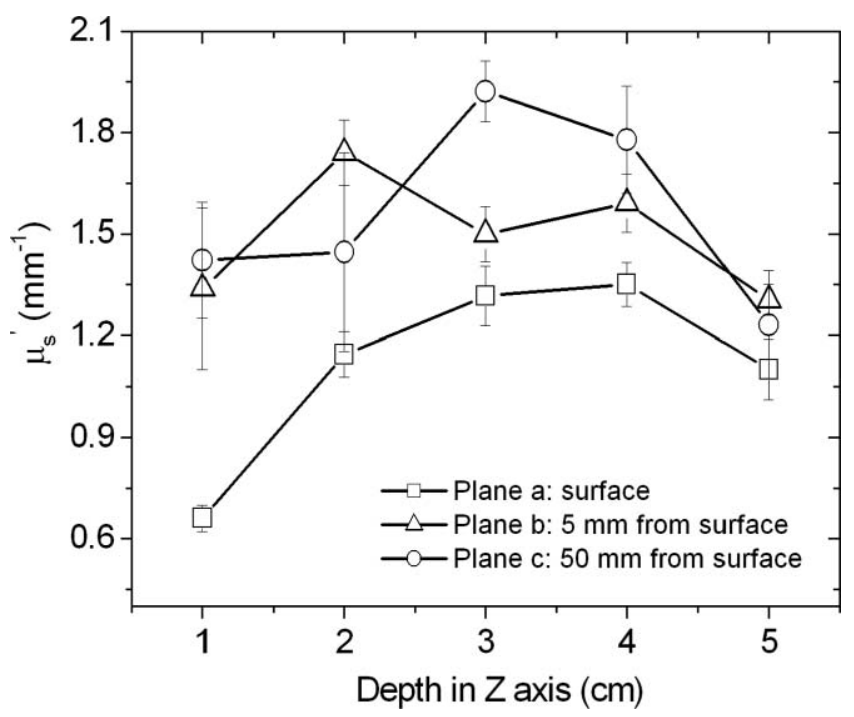

Fig. 7 Measured $\mu_{s}^{\prime}$ distribution at $784 \mathrm{~nm}$ inside the large PVA phantom. Data points represent average $\mu_{s}^{\prime}$ value of 5 measurements from the plane $a$, plane $b$ and plane $c$ of the phantom shown in Fig. 5. The error bars represent the standard deviations.

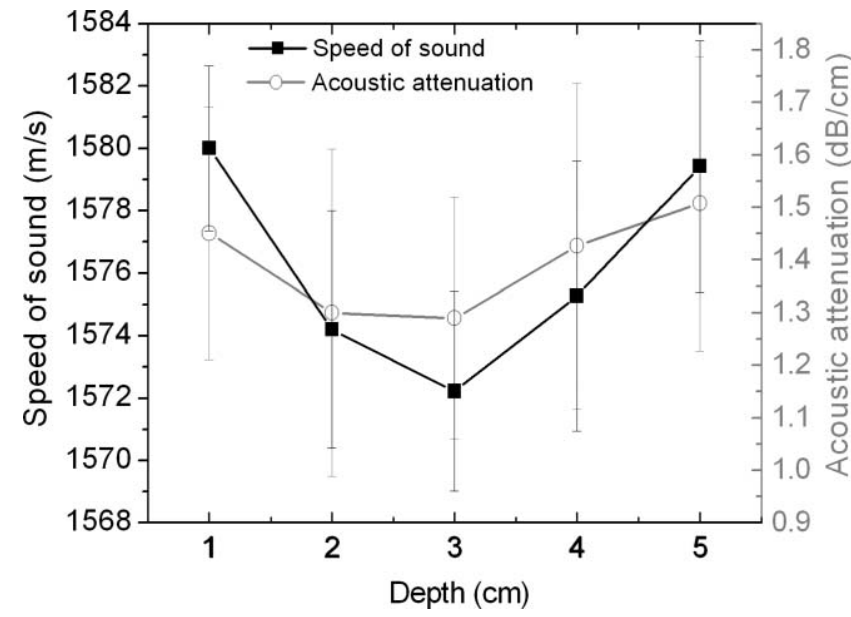

Fig. 8 Speed of sound and acoustic attenuation (at $5 \mathrm{MHz}$ ) at different depths from the surface to the bulk of large PVA phantom at $22.5^{\circ} \mathrm{C}$. The data points represent the average values from 10 measurements, error bars represent the standard deviations.

1.33 (water) and 1.5 (most polymers). The corresponding variations are less than $10 \%$. This ensures a weak dependence of the determination of $\mu_{s}^{\prime}$ on refractive index variation.

\subsection{Speed of Sound and Acoustic Attenuation Measurements}

The SOS and AA measured in specimens located at different depths from the surface down into the bulk of the large PVA phantom are shown in Fig. 8. Though their standard deviations are relatively high due to roughness of the sample surfaces caused by cutting leading to dispersions in thickness estimation (standard deviations $\pm 0.5 \mathrm{~mm}$ ), in general the SOS values obtained are comparable to the values reported for biological tissue. SOS is usually quoted as between 1425 and $1575 \mathrm{~m} \mathrm{~s}^{-1}$, (Ref. 24) and AA between 0.5 and $1.1 \mathrm{~dB} \mathrm{~cm}^{-1}$ at $1.76 \mathrm{MHz}^{37}$ Both SOS and AA decrease slightly from the surface toward the center of the phantom. The spatial variation in the acoustic properties, however, is within $1 \%$ for SOS and less than around $13 \%$ for AA.

\subsection{Microstructures of PVA Gels}

Besides 10 to $20 \mu \mathrm{m}$ large cavities on the surface (Fig. 5), the SEM micrograph of a deep cross-section and of the surface show similar small scale pores (less than $1 \mu \mathrm{m}$ ), almost uniformly distributed throughout the entire specimen area (Fig. 9). Figure 10(b) summarizes the average pore size at the locations specified in Figure 10(a) with their standard deviation. It also compares these dimensions with the small scale pores which are located at the outer surface [sample 0 in Figs. 10(a) and 10(b)). Within the same specimen, the pore size variability is considerable, but the overall distribution does not exhibit any particular trend. The average pore size in the bulk is sub-micrometer and smaller than in Hyon et al. ${ }^{38}$ if the large 10 to $20 \mu \mathrm{m}$ structures present at the outer surfaces are discarded.

Estimates of the wall thickness are shown in Fig. 10(c), along with the number of pores in the specified ROI. The pore size 

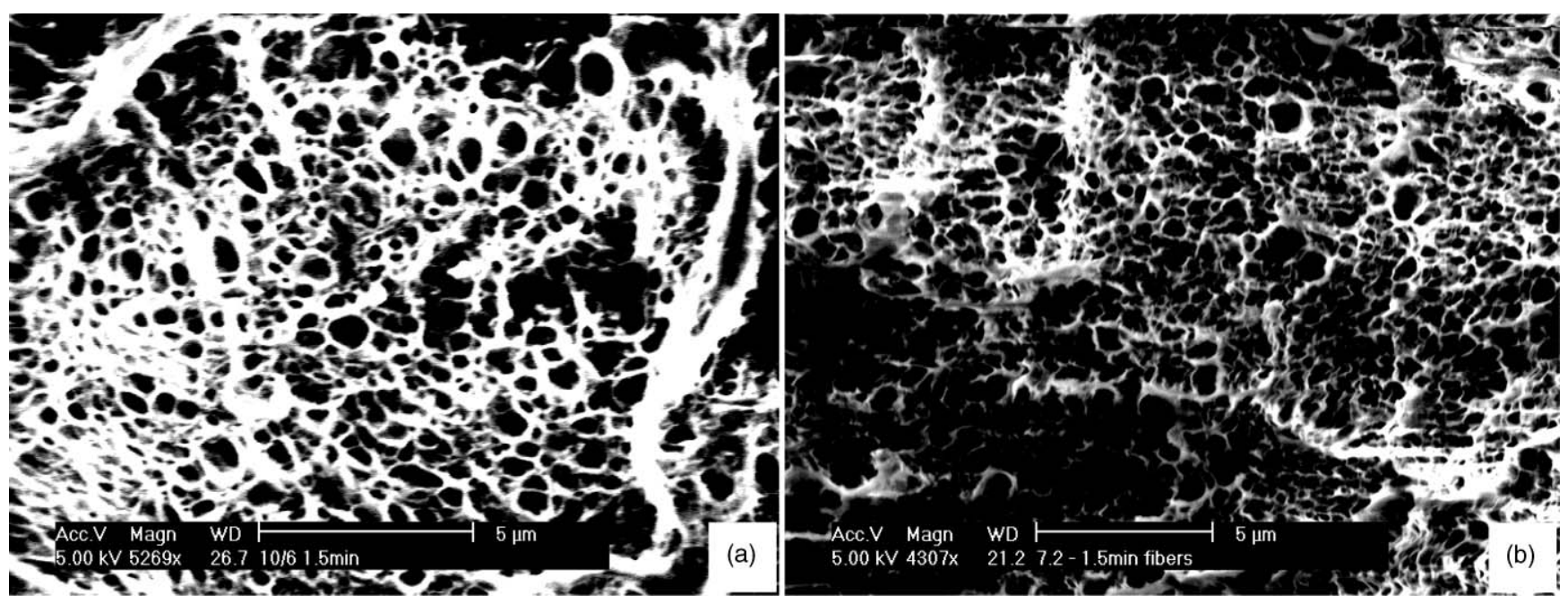

Fig. 9 Scanning electron microscope imaging of liquid nitrogen preprocessed specimens situated at (a) surface and (b) a deep lying cross-sections.

does not change, but a difference is found in density and wall thickness. Bulk specimens (groups 3 and 4) exhibit lower wall thickness (approximately $-25 \%$ ) than side specimens (groups 1 and 2) as shown in Fig. 10(d). Thus, pore density increases toward the center of the phantom.

\section{Discussion}

Kharine et al. ${ }^{7}$ introduced PVA as a suitable material for photoacoustic mammography utilizing its known acoustic property similarity with tissue, while fine tuning its optical properties. The optical properties were characterized in that work on specially prepared small test specimens. Since the gels are formed using $\mathrm{F}-\mathrm{T}$, it is to be expected that temperature responses of larger gels will be spatially nonuniform. We also investigated spatial distribution of optical (and acoustic) properties as this may be related to the temperature during the $\mathrm{F}-\mathrm{T}$ process. As the optical absorption is only dependent on the molecular structure of the material, the intrinsic absorption is not F-T dependent, and at the wavelength of interest it is appropriate for breast tissue phantom $;^{7}$ this parameter was not measured during the experiments. We focused on optical reduced scattering coefficient, speed of sound, and acoustic attenuation. The $\mu_{s}^{\prime}$, was measured using ODR. Finally, we inspected the microstructure using scanning electron microscopy.

Temperature monitoring showed significant differences from the surface to the bulk (Fig. 6). When the temperature monitoring is begun, with the aqueous PVA solution in the mold, there is a difference of $15^{\circ} \mathrm{C}$ between the two thermocouple readings. When the surface temperature reaches water freezing point, the bulk temperature is still above $10^{\circ} \mathrm{C}$. It takes a further $3 \mathrm{~h}$ for the bulk to start freezing.

In general, the values of $\mu_{s}^{\prime}$ measured are in the range of values quoted for breast tissue. ${ }^{39}$ There is a substantial difference between surface and interior values $\left(0.6\right.$ to $1.9 \mathrm{~mm}^{-1}$ ) (see Fig. 7). Within the bulk the maximum variation is about $30 \%$ (1.2 to $1.9 \mathrm{~mm}^{-1}$ ). From the distribution, a two-layer structure may be observed: a center region with higher values and an outer shield region of a roughly $5 \mathrm{~mm}$ thickness having lower values.
It is interesting that this structure matches the standard two-layer breast model used for dosimetry in $\mathrm{x}$ ray mammography. ${ }^{40}$ The breast is modelled as having an inner region composed of a mixture of adipose and glandular tissue, and an outer layer of predominantly adipose tissue of $5 \mathrm{~mm}$ thickness. We surveyed the literature concentrating on $\mu_{s}^{\prime}$ distribution for breast in vivo at the wavelength range we used. Brooksby et al. ${ }^{41}$ imaged the distribution in breast in vivo using MRI guided near-infrared tomography at wavelength of $785 \mathrm{~nm}$. The MRI image shows the breast to be clearly divided into an outer adipose tissue layer and an internal glandular area. Comparing MRI findings with the scattering distribution it can be observed that a low scattering area $\left(0.93 \mathrm{~mm}^{-1}\right)$ is associated to the adipose tissue, and a higher scattering area $\left(1.12 \mathrm{~mm}^{-1}\right)$ matches the glandular tissue. Similar behavior has been reported in Refs. 42 and 43 in vivo and Refs. 39,44 , and 45 ex vivo. Thus, we find that the PVA gel sample fortuitously mimics the distribution of adipose tissue and glandular tissue in the breast. While this makes it an excellent breast phantom, in applications where more homogeneous samples are required the 5-mm thick surface layer can be removed using a scalpel.

The SOS and AA values show relatively homogeneous distribution (Fig. 8) with a slight decrease in values toward the center. The values and their variations are within the range of acoustic properties of the breast.

Microstructural inspection of the surface has revealed two different scale structures: large cavities of several micrometers and these filled with sub-micrometer pores. In the interior, we found only the smaller pores with an average diameter of $0.35 \mu \mathrm{m}$. Even though the pore-size dispersion is quite high, no trend is observed as a function of location whether at the surface or in the interior. However, we observe a difference in the spacing between pores in the bulk, with pores being closer-packed toward the center. [see Figs. 10(c) and 10(d)].

We expect that because pore densities increase, while largely maintaining the same diameters, the interiors will possess a higher water volume fraction. This can explain the lower SOS and AA measured in the bulk (see also Ref. 46). The pore density variations are also responsible for the observed spatial distribution of optical properties: the pore-denser regions provide more 


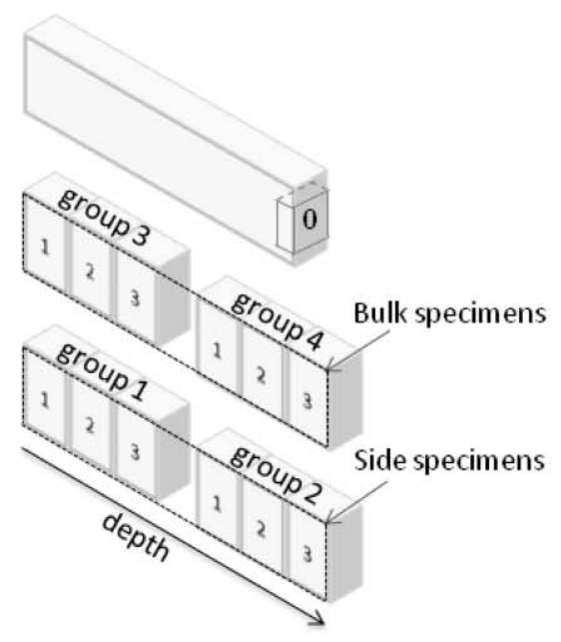

(a)

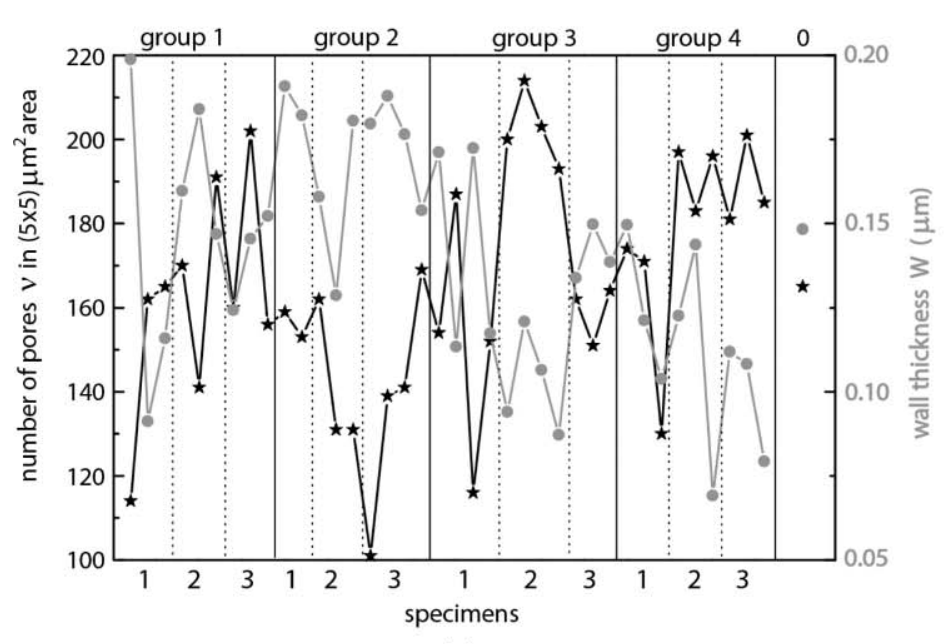

(c)

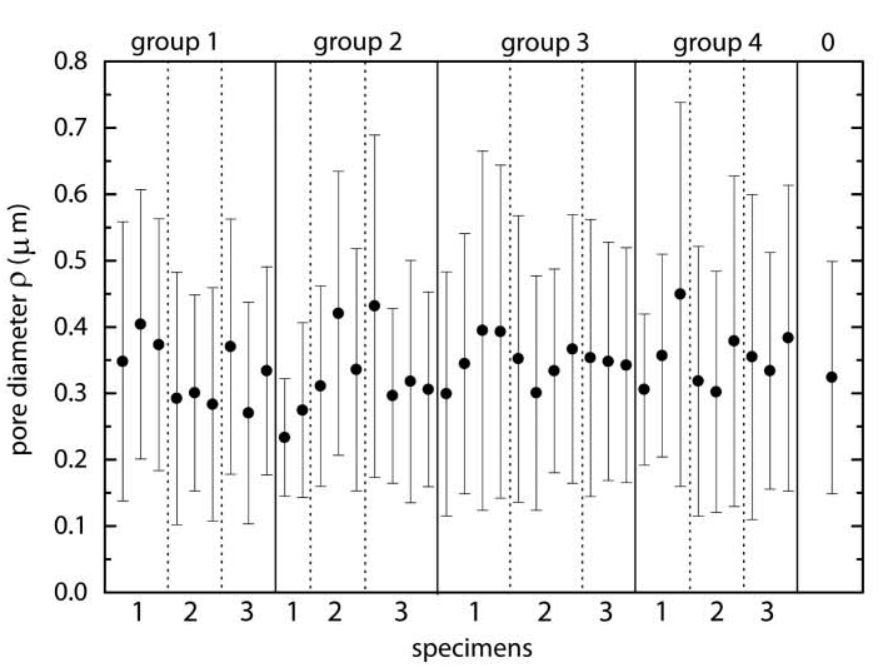

(b)

Fig. 10 (a) Schematic of block III in Fig. 5. (b) Pore sizes in the locations specified in (a), the error bars represent the standard deviations. (c) Pore density (black stars, left axis) and estimate of wall thickness (gray dots, right axis) for all specimens. (d) Pore diameter and wall thickness for grouped sample in depth. The error bars represent the standard deviations.

scattering events which explains the slight $\mu_{s}^{\prime}$ increase toward the center, while the pore sizes are relatively constant in the bulk. At the surface layers the converse occurs with relatively lower pore densities and further, the larger 10 to $20 \mu \mathrm{m}$ cavities show lower $\mu_{s}^{\prime}$ than the wavelength-sized sub-micrometer pores inside.

The reason for the spatial distribution of pore characteristics is not yet understood. We made a first effort to resolve this by exposing the entire volume of aqueous PVA solution and the forming gel to a uniform temperature. The F-T cycles were applied using an external temperature control of the refrigerator, where the rate of cooling (warming) was set to $2{ }^{\circ} \mathrm{C} /$ hour while the difference between surface and interior thermocouple readings was set to be less than $2{ }^{\circ} \mathrm{C}$. A freezing cycle in such a case took $60 \mathrm{~h}$ untill the block was uniformly cooled to $-20^{\circ} \mathrm{C}$. The distribution of optical scattering distribution was only marginally better. This suggests that the mechanism responsible for the variation in pore characteristics may have to do with internal stresses exerted at the interior compared to

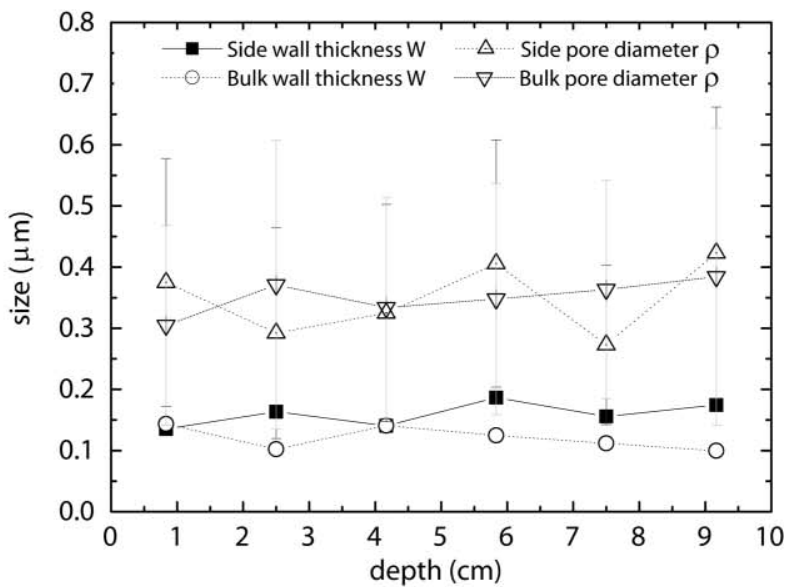

(d) 
tissue mixture, and an outer layer of predominantly adipose tissue. If this optical property variation is not acceptable in an application, we recommend removal of the superficial layer to a depth of around $5 \mathrm{~mm}$.

\section{Acknowledgments}

We acknowledge Professor Jeremy C. Hebden (Department of Medical Physics and Bioengineering, University College London, United Kingdom) and Professor Ernest L. Madsen (Department of Medical Physics, University of Wisconsin, Wisconsin) for providing the calibrated optical and acoustic samples, respectively. The financial support of the Agentschap NL Innovation Oriented Research Programmes Photonic Devices under the HYMPACT Project (IPD083374) is gratefully acknowledged.

\section{References}

1. R. J. Nordstrom, "Phantoms as standards in optical measurements," Proc. SPIE 7906, 79060H (2011).

2. L. V. Wang, "Multiscale photoacoustic microscopy and computed tomography," Nature Photon. 3, 503-509 (2009).

3. D. Piras, W. Xia, W. Steenbergen, T. G. van Leeuwen, and S. Manohar, "Photoacoustic imaging of the breast using the twente photoacoustic mammoscope: Present status and future perspectives," IEEE J. Sel. Top. Quantum Electron. 16, 730-739 (2010).

4. R. A. Kruger, R. B. Lam, D. R. Reinecke, S. P. D. Rio, and R. P. Doyle, "Photoacoustic angiography of the breast," Med. Phys. 37, 6096-6100 (2010).

5. S. A. Ermilov, T. Khamapirad, A. Conjusteau, M. H. Leonard, R. Lacewell, K. Mehta, T. Miller, and A. A. Oraevsky, "Laser optoacoustic imaging system for detection of breast cancer," J. Biomed. Opt. 14(2), 024007 (2009).

6. T. D. Kholhlova, I. M. Prelivanov, V. V. Kozhushko, A. N. Zharinov, V. S. Solomatin, and A. A. Karabutov, "Optoacousitc imaging of absorbing objects in a turbid medium: ultimate sensitivity and application to breast cancer diagnostics," Appl. Opt. 46, 262-272 (2007).

7. A. Kharine, S. Manohar, W. Steenbergen, R. G. M. Kolkman, R. A. Bolt, and F. F. M. de Mul, "Poly(vinyl alcohol) gels for use as tissue phantoms in photoacoustic mammography," Phys. Med. Biol. 48, 357-370 (2003).

8. S. Manohar, A. Kharine, J. C. G. van Hespen, W. Steenbergen, F. F. M. de Mul, and T. G. van Leeuwen, "Photoacoustic imaging of inhomogeneities embedded in breast tissue phantoms," Proc. SPIE 4960, 64-75 (2003).

9. S. Sethuraman, S. Aglyamov, J. Amirian, R. Smalling, and S. Emelianov, "Intravascular photoacoustic imaging to detect and differentiate atherosclerotic plaques," Proc. IEEE Int. Ultrasonics Symposium, pp. 133-136 (2005).

10. J. L. Su, B. Wang, and S. Y. Emelianov, "Photoacoustic imaging of coronary artery stents," Opt. Express 17, 19894-19901 (2009).

11. C. U. Devi, R. M. Vasu, and A. K. Sood, "Design, fabrication, and characterization of a tissue-equivalent phantom for optical elastography," J. Biomed. Opt. 10(4), 044020 (2005).

12. C. M. Hassan, and N. A. Peppas, "Structure and application of poly(vinyl alcohol) hydrogels produced by conventional crosslinking or by freezing/thawing methods," Adv. Polymer. Sci. 153, 37-65 (2000).

13. V. Pazos, R. Mongrain, and J. C. Tardif, "Polyvinyl alcohol cryogel: Optimizing the parameters of cryogenic treatment using hyperelastic models," J. Mech. Behav. Biomed. Mater. 2, 542-549 (2009).

14. M. Nambu, T. Watari, T. Sakamoto, and K. Akojima, "Method for applying electromagnetic wave and ultrasonic wave therapies," US Patent No. 4,958,626 (1990).

15. K. Zell, J. I. Sperl, M. W. Vogel, R. Niessner, and C. Haisch, "Acoustic properties of selected tissue phantom materials for ultrasound imaging," Phys. Med. Biol. 52, 475-484 (2007).

16. I. Mano, H. Goshima, M. Nambu, and M. Lio, "New polyvinyl alcohol gel material for mri phantoms," Magn. Reson. Med.3, 921-926 (1986).
17. K. C. Chu and B. K. Rutt, "Polyvinyl alcohol cryogel: an idea phantom material for $\mathrm{mr}$ studies of arterial flow and elasticity," Magn. Reson. Med. 37, 314-319 (1997).

18. S. Manohar, A. Kharine, J. C.G. van Hespen, W. Steenbergen, and T. G. van Leeuwen, "Photoacoustic mammography laboratory prototype: imaging of breast tissue phantoms," J. Biomed. Opt. 9(6), 11721181 (2004).

19. V. I. Lozinsky and L. Damshkaln, "Study of cryostructuration of polymer systems. xvii. poly(vinyl alcohol) cryogels: Dynamics of the cryotropic gel formation," J. Appl. Polymer Sci. 77, 2017-2023 (2000).

20. N. A. Peppas, "Turbidimetric studies of aqueous poly(vinyl alcohol) solutions," Makromol. Chem. 176, 3433-3340 (1975).

21. L. Wang and S. L. Jaques, "Use of a laser beam with an oblique angle of incidence to measure the reduced scattering coefficient of a turbid medium," Appl. Opt. 13, 2362-2366 (1995).

22. M. Firbank and D. T. Delpy, "Design for a stable and reproducible phantom for use in near infra-red imaging and spectroscopy," Phys. Med. Biol. 38, 847-853 (1993).

23. H. J. van Staveren, C. J. M. Moes, J. van Marie, S. A. Prahl, and M. J. C. van Gemert, "Light scattering in intralipid-10\% in the wavelength range of 400-1100 nm," Appl. Opt. 30, 4507-4514 (1991).

24. J. Bamber, Acoustic Characteristics of Biological Media, Wiley, New York, (1997).

25. J. Lubbers and R. Graaff, "A simple and accurate formula for the sound velocity in water," Ultrasound Med. Biol. 24, 1065-1069 (1998).

26. K. R. Waters and J. G. Miller, "Causality-imposed (kramers-krönig) relationships between attenuation and dispersion," IEEE Trans. Ultrason. Ferroelecte Freq. Control 52, 822-834 (2005).

27. K. R. Waters, M. S. Hughes, J. Mobley, G. H. Brandenburger, and J. G. Miller, "On the applicability of Kramers-Krönig relations for ultrasonic attenuation obeying a frequency power law," J. Acoust. Soc. Am. 108, 556-563 (2000).

28. K. V. Gurumurthy and R. M. Arthur, "A dispersive model for the propagation of ultrasound in soft tissue," Ultrason. Imaging 4, 355-377 (1982).

29. R. G. Willemink, S. Manohar, K. H. Slump, F. van der Heijden, and T. G. van Leeuwen, "A maximum likelihood method for obtaining integrated attenuation transmission mode measurements," Acoustics'08 Paris pp. 5179-5184(2008).

30. E. L. Madsen, G. R. Frank, and F. Dong, "Liquid or solid ultrasonically tissue-mimicking materials with very low scatter," Ultrasound Med. Biol. 24, 535-542 (1998).

31. R. B. Chin, E. L. Madsen, J. A. Zagzebski, H. Jadvar, X. K. Wu, and G. R. Frank, "A reusable perfusion supporting tissue-mimicking material for ultrasound hyperthermia phantoms," Med Phys 17, 380-390 (1990).

32. K. A. Wear, T. A. Stiles, G. R. Frank, E. L. Madsen, F. Cheng, E. J. Feleppa, C. S. Hall, B. S. Kim, P. Lee, W. D. O'Brien, M. L. Oelze, B. I. Raju, K. K. Shung, T. A. Wilson, and J. R. Yuan, "Interlaboratory comparison of ultrasonic backscatter coefficient measurements from 2 to $9 \mathrm{MHz}, "$ J. Ultrasound Med. 24, 1235-1250 (2005).

33. S. H. Hyon and Y. Ikada, "Porous and transparent poly(vinyl alcohol) gel and method of manufacturing the same," US Patent, No. 4,663,358 (1987).

34. H. H. Trieu and S. Qutubuddin, "Polyvinyl alcohol hydrogels I. Microscopic structure by freeze-etching and critical point drying techniques," Colloid Polym. Sci. 10, 3015-3022 (1994).

35. L. Martin, M. Alonso, A. Girotti, F. J. Arias, and C. Rodriguez-Cabello, "Synthesis and characterization of macroporous thermosensitive hydrogels from recombinant elastin-like polymers," Biomacromolecules 10(11), 3015-3022 (2009).

36. F. Yokoyama, and L. M. Shimamura, T. Ikawa, and K. Monobe, "Morphology and structure of highly elastic poly(vinyl alcohol) hydrogel prepared by repeated freezing-and-melting," Colloid Polym. Sci. 264, 564-601 (1986).

37. F. A. Duck, Physical Properties of Tissue: A Comprehensive Reference Book, Academic, London (1990).

38. S. H. Hyon, W. Cha, and Y. Ikada, "Preparation of transparent poly(vinyl alcohol) hydrogel," Polymer Bull. 29, 119-122 (1989). 
39. V. G. Peters, D. R. Wyman, M. S. Patterson, and G. L. Frank, "Optical properties of normal and diseased human breast tissues in the visible and near infrared," Phys. Med. Biol. 35, 1317-1334 (1990).

40. D. R. Dance, "Monte Carlo calculation of conversion factors for the estimation of mean glandular breast dose," Phys. Med. Biol. 35, 12111219 (1990).

41. B. Brooksby, S. J. Jiang, H. Dehghani, B. W. Pogue, K. D. Paulsen, C. Kogel, M. Doyley, J. B. Waeaver, and S. P. Poplack, "Magnetic resonance-guided near-infrared tomography of the breast," Rev. Sci. Instrum. 75, 5262-5270 (2004).

42. Q. Fang, S. A. Carp, J. Selb, G. Boverman, Q. Zhang, D. B. Kopans, R. H. Moore, E. L. Miller, D. H. Brooks, and D. A. Boas, "Combined optical imaging and mammography of the healthy breast: Optical contrast derived from breast structure and compression," IEEE Trans. Med. Imaging 28, 30-42 (2009).
43. Q. Fang, J. Selb, S. A. Carp, G. Boverman, E. L. Miller, D. H Brooks, R. H. Moore, D. B. Kopans, and D. A. Boas, "Combined optical and x-ray tomosynthesis breast imaging," Radiology 258, 89-97 (2010).

44. G. M. Palmer, C. Zhu, T. M. Breslin, F. Xu, K. W. Gilchrist, and N. Ramanujam, "Monte carlo-based inverse model for calculating tissue optical properties. part ii: Application to breast cancer diagnosis," Appl. Opt. 45, 1072-1078 (2006).

45. H. L. Fu, B. Yu, J. Y. Lo, G. M. Palmer, T. F. Kuech, and N. Ramanujam, "A low-cost, portable, and quantitative spectral imaging system for application to biological tissues," Opt. Express 18, 1263012644 (2010).

46. P. Chiarelli, A. Lanatä, and M. Carbon, "Acoustic waves in hydrogels: A bi-phasic model for ultrasound tissue-mimicking phantom," Mater Sci. Eng. C 29, 899-907 (2009). 